\title{
Chemically Amplified Photosensitive Poly(benzoxazole)
}

\author{
Kazuya Ebara, Yuji Shibasaki, and Mitsuru Ueda* \\ Department of Organic and Polymeric Materials \\ Graduate School of Science and Engineering, Tokyo Institute of Technology, \\ 2-12-1 O-okayama, Meguro-ku, Tokyo 152-8552, Japan \\ mueda@polymer.titech.ac.jp
}

\begin{abstract}
A novel chemically amplified photosensitive poly (benzoxazole) (PBO) precursor based on partially tert-buthoxycarbonylated ( $t$-BOC) poly (o-hydroxyamide) having norbornene end-capping groups 5 and diphenyliodonium-9,10-dimethoxyantracene-2-sulfonate (DIAS) as a photo-acid generator has been developed. The resist showed a sensitivity of $60 \mathrm{~mJ} \mathrm{~cm}$ and a contrast of 2.5 when it was exposed to $365 \mathrm{~nm}$ light, followed by post-baking at $120{ }^{\circ} \mathrm{C}$ for $5 \mathrm{~min}$ and developing with $2.38 \mathrm{wt} \%$ aqueous tetramethylammonium hydroxide (TMAH) solution at $25^{\circ} \mathrm{C}$. A fine positive image featuring $10 \mu \mathrm{m}$ line and space patterns was obtained on the film exposed to $100 \mathrm{~mJ} \mathrm{~cm}^{-2}$ of UV-light at $365 \mathrm{~nm}$ by the contact mode. By heat treatment at $350{ }^{\circ} \mathrm{C}$ for $\mathrm{lh}$, this positive image gave the cross-linked PBO retaining its original shape that indicated high durability during thermal process.
\end{abstract}

Keywords: Photosensitivity, Poly(benzoxazole), Photoacid generator, Norbornene end-capping , Chemical amplification

\section{Introduction}

Photosensitive poly(benzoxazole)s (PBO)s are attracting great attention as photosensitive and thermally stable polymers because of their high mechanical strength, thermal stability, and low dielectric constant. One of the most promising system is a formation composed of a PBO precursor, poly(o-hydroxyamide) (PHA) and a diazonaphthoquinone photosensitizer [1-3]. Hydroxyl groups of the PBO precursor are desirable as base-soluble functional groups for alkaline developable photosensitive resists just like novolac-resin resists. Furthermore, hydroxyl groups, which usually increase the dielectric constant, can be transformed into benzoxazoles by thermal treatment of PHA.

In a previous paper, we reported a novel direct resist formulation method for photosensitive PBO, where the polymerization solution from diphenyl isophthalate 1 and bis(o-aminophenol) 2 was mixed with diazonaphthoquinones for the formulation of resist [4]. It's sensitivity was $110 \mathrm{~mJ}$ $\mathrm{cm}^{-2}$ with $365 \mathrm{~nm}$ light. The sensitivity of a photoresist to exposure is important parameters for the design of photoresist materials. Highly sensitive resists that require low exposure doses are desirable to maximize the throughput of wafers in exposure tools.

Photosensitive polymers with high sensitivity have been developed using polyimides having tert-buthoxycarbonyloxy ( $t$-BOC) substituents in conjunction with a photo-acid generator (chemical amplification system) [5]. To improve the sensitivity of photosensitive PBOs, the chemically amplified technique is applied. Furthermore, polymers with low molecular weights are reported to be preferred in the lithographic process [6].

This article describes the development of a novel chemically amplified photosensitive PBO precursor based on partially $t$-BOC protected PHA having norbornene end-capping groups.

\section{Experimental}

\subsection{Materials}

Diphenyl isophthalate (1) and 4,4'-(hexafluoroisopropylidene)bis(o-aminophenol 
) (2) were recrystallized from toluene and hexane/tetrahydrofuran (THF), respectively. 1-Methyl-2-pyrrolidinone (NMP) was purified by vacuum distillation from calcium hydride and stored over 4A molecular sieves. Diphenyliodonium-9,10-dimethoxyantracene-2sulfonate (DIAS) was prepared according to the reported procedure [5] (Scheme 1). Other reagents and solvents were used as received.

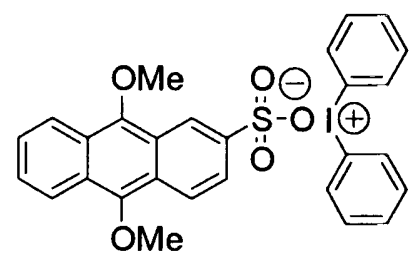

Scheme 1 Structure of DIAS

2.1.2. Synthesis of 5-norbornene-2-carboxylic anhydride (4)

To a solution of 5-norbornene-2-carboxylic acid $(1.464 \mathrm{~g}, 10 \mathrm{mmol})$ and triethylamine (TEA) $(0.536 \mathrm{~mL}, 10 \mathrm{mmol})$ in dichloromethane $(10 \mathrm{~mL})$ was added dropwise a solution of diphenylphospholyl chloride $(1.22 \mathrm{~g}, 5 \mathrm{mmol})$ in dichloromethane $(10 \mathrm{~mL})$. After $1 \mathrm{~h}$ the mixture was poured into water. The organic layer was separated, washed with water, and dried over $\mathrm{MgSO}_{4}$. The solvent was evaporated under reduced pressure. The crude oil was distilled under vacuum $\left(142-145^{\circ} \mathrm{C} / 10 \mathrm{mmHg}\right.$ ). The yield was $45 \%$. IR $(\mathrm{KBr}): v\left(\mathrm{~cm}^{-1}\right) 2950\left(\mathrm{CH}_{2}\right), 1808,1734(\mathrm{C}=\mathrm{O})$, $1700 \quad(\mathrm{C}=\mathrm{C})$, and $713 \quad(-\mathrm{CH}=\mathrm{CH}-) .{ }^{1} \mathrm{H}$ NMR $\left(\mathrm{CDCl}_{3}\right): \delta(\mathrm{ppm})$ 6.23-5.99 (m, 4H), 3.25-2.96 (m, $6 \mathrm{H}), 2.19-1.89(\mathrm{~m}, 2 \mathrm{H}), 1.53-1.29(\mathrm{~m}, 6 \mathrm{H}), 7.85(\mathrm{~s}$, $1 \mathrm{H}), 7.64(\mathrm{t}, J=8.0 \mathrm{~Hz}, 1 \mathrm{H}), 7.01(\mathrm{brs}, 4 \mathrm{H})$.

\subsubsection{Synthesis of end-capped poly (o-hydroxyamide) (3)}

Monomers 1 ( $0.636 \mathrm{~g}, 1.8 \mathrm{mmol}), 2(0.732 \mathrm{~g}, 2.0$ $\mathrm{mmol})$, and NMP $(5.6 \mathrm{~mL})$ were placed in a $10 \mathrm{~mL}$ round-bottom flask under $\mathrm{N}_{2}$. The solution was heated at $185{ }^{\circ} \mathrm{C}$ for $6 \mathrm{~h}$ and then cooled to room temperature. End capping reagent $4(0.155 \mathrm{~g}, 0.6$ mmol) in NMP ( $1 \mathrm{~mL}$ ) was added to this solution and reacted further for $3 \mathrm{~h}$, and poured into an aqueous methanol solution $(1: 1$ in volume ratio $200 \mathrm{ml}$ ) to precipitate the polymer. The obtained polymer was washed with water and dried in vacuo over $\mathrm{P}_{2} \mathrm{O}_{5}$. The yield was $94 \%$. IR $(\mathrm{KBr}): y\left(\mathrm{~cm}^{-1}\right)$ $3300(\mathrm{OH}), 1654(\mathrm{C}=\mathrm{O}), 1608(\mathrm{Ar})$, and $1253\left(\mathrm{CF}_{3}\right)$. ${ }^{1} \mathrm{H}$ NMR (DMSO- $d_{6}$ ): $\delta$ (ppm) 10.0 (brs, 2H), 9.62 $(\mathrm{s}, 2 \mathrm{H}), 8.51(\mathrm{~s}, 2 \mathrm{H}), 8.12(\mathrm{~d}, J=8.0 \mathrm{~Hz}, 2 \mathrm{H}), 7.85$ $(\mathrm{s}, 1 \mathrm{H}), 7.64(\mathrm{t}, J=8.0 \mathrm{~Hz}, 1 \mathrm{H}), 7.01$ (brs, $4 \mathrm{H})$.

\subsubsection{Synthesis} of poly[o-(4-tert-butoxycarbonyloxy)hydroxyamide] (5b) : General procedure

To a solution of polymer $3(0.496 \mathrm{~g} 1.0 \mathrm{mmol})$ and $N, N$-dimethylaminopyridine (DMAP) $(0.014 \mathrm{~g}$ $0.05 \mathrm{mmol})$ in NMP was added di-tert-butyl dicarbonate $(0.218 \mathrm{~g}, 1.0 \mathrm{mmol})$. The solution was stirred for $1 \mathrm{~h}$ at room temperature, and was poured into $1 \mathrm{M}$ aqueous hydrogen chloride solution (200 $\mathrm{mL}$ ). The precipitate was collected by filtration, washed with water and dried in vacuo at $60{ }^{\circ} \mathrm{C}$ for $24 \mathrm{~h}$. The yield was $94 \%$. IR $(\mathrm{KBr}): v\left(\mathrm{~cm}^{-1}\right) 3300$ $(\mathrm{OH}), 2950\left(\mathrm{CH}_{3}\right), 1766,1654(\mathrm{C}=\mathrm{O}), 1608(\mathrm{Ar})$, and $1253\left(\mathrm{CF}_{3}\right)$. ${ }^{1} \mathrm{H}$ NMR (DMSO- $\left.d_{6}\right): \delta(\mathrm{ppm})$ 10.0 (brs, 2H), 9.70-9.62 (m, $1 \mathrm{H}), 8.51(\mathrm{~s}, 1 \mathrm{H})$, 8.14-8.1 (m, 2H), $8.12(\mathrm{t}, J=8.0 \mathrm{~Hz}, 1 \mathrm{H}), 7.80(\mathrm{~s}$, $1 \mathrm{H}), 7.65(\mathrm{t}, J=8.0 \mathrm{~Hz}, 1 \mathrm{H}), 7.42(\mathrm{t}, J=8.0 \mathrm{~Hz}$, 1H), .7.22 (s, 1H), 7.01 (brs, 2H), $1.39(\mathrm{~s}, 9 \mathrm{H})$.

\subsection{Dissolution rate}

DIAS was added to a polymer solution (30 wt $\%$ of the total solid) to construct a photosensitive polymer. The polymer film spin-cast on a silicon wafer was pre-baked at $80^{\circ} \mathrm{C}$ for $3 \mathrm{~min}$, and then exposed to a filtered super-high pressure mercury lamp at $365 \mathrm{~nm}$. The exposed film was developed with a $2.38 \mathrm{wt} \%$ aqueous tetramethylammonium hydroxide (TMAH) solution at $25^{\circ} \mathrm{C}$, and rinsed in water. The changes in the film thickness against the exposure energy were measured by a Detak $^{3}$ surface profiler (Veeco Instument Inc.).

\subsection{Photosensitivity}

A $1.0 \mu \mathrm{m}$-thick polymer film on a silicon wafer was exposed to radiation at a wavelength of 365 $\mathrm{nm}$ through the filtered super high-pressure mercury lamp, developed with a $2.38 \mathrm{wt} \%$ aqueous TMAH solution at $25{ }^{\circ} \mathrm{C}$, and rinsed with water. A characteristic curve was obtained by a normalized film thickness against exposure energy. Imagewise exposure through a mask was carried out in a contact-printing mode.

\subsection{Measurement}

The infrared spectra were recorded on a Horiba FT-210 spectrophotometer. ${ }^{1} \mathrm{H}-\mathrm{NMR}$ spectra were recorded on a Bruker GPX300 (300MHz) spectrometer. UV spectra were obtained on a Jasco V-650 spectrophotometer. Thermal analyses were performed on a Seiko thermal analyzer at a heating 
rate of $10{ }^{\circ} \mathrm{C} / \mathrm{min}$ for thermogravimetry (TG). Molecular weights were determined by a gel permeation chromatograph (GPC) with polystyrene calibration using a Tosoh HPLC-8120-G equipped with consecutive TSK gel columns $\mathrm{GMH}_{\mathrm{HR}}-\mathrm{M}$ and $\mathrm{GMH}_{\mathrm{HR}}-\mathrm{L}$ at $40^{\circ} \mathrm{C}$ in DMF containing 0.01 $\mathrm{mol} / \mathrm{L} \mathrm{LiBr}$. The film thickness was measured by a Dektak ${ }^{3}$ surface profiler (Veeco Instrument Inc).

\section{Results and Discussion}

\subsection{Polymer synthesis}

As described in the introduction, a low molecular weight polymer is needed to get a high resolution without sacrificing thermal stability. End-capping groups that lead to cross-linked network without gas evolution are useful to control molecular weights. Norbornene-terminated imide (bisnadiimide) resins have been used in industry [7]. Thus, a norbornene group as an end-capping was selected in this study.

PHA was prepared from 1 and 2 with their molar ratio of $0.9: 1$ in NMP at $185^{\circ} \mathrm{C}$ for $6 \mathrm{~h}$, and then converted end-capped PHA 3 by treating with 5-norbornene-2-carboxylic anhydride 4 as an end-capping agent (eq.1).

The structure of $\mathbf{3}$ was characterized by IR and ${ }^{1} \mathrm{H}$ NMR spectroscopy.

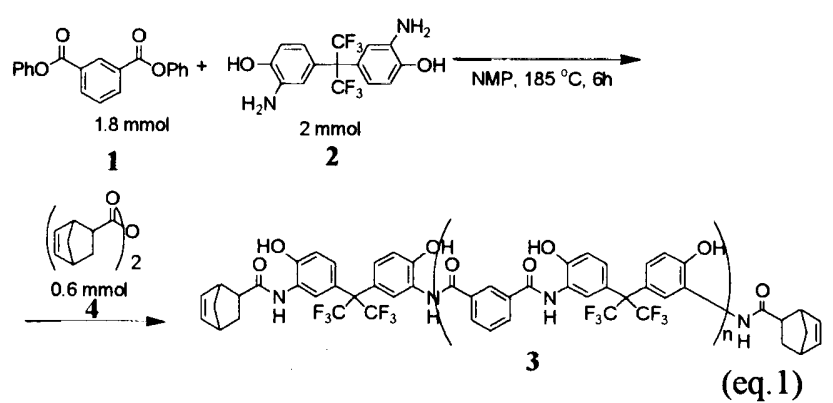

The IR spectrum of 3 exhibited characteristic absorptions at $3300,1654,1253 \mathrm{~cm}^{-1}$ due to the $\mathrm{O}-\mathrm{H}, \quad \mathrm{C}=\mathrm{O}$ (amide), and $\mathrm{C}-\mathrm{F}$ stretchings, respectively. Figure 1 shows the ${ }^{1} \mathrm{H}$ NMR spectrum of polymer 3 with the assignment of each peak. Signals assignable to terminal norbornene protons (peaks 8-10) were observed at 6.0, 2.9, $1.3 \mathrm{ppm}$, respectively.

The molecular weight of polymer 3 was determined by GPC in DMF at $40{ }^{\circ} \mathrm{C}$. The chromatogram showed a unimodal distribution with $M_{\mathrm{n}}$ and $M_{\mathrm{w}}$ of 4000 and 5800 , respectively, with polystyrene standards.

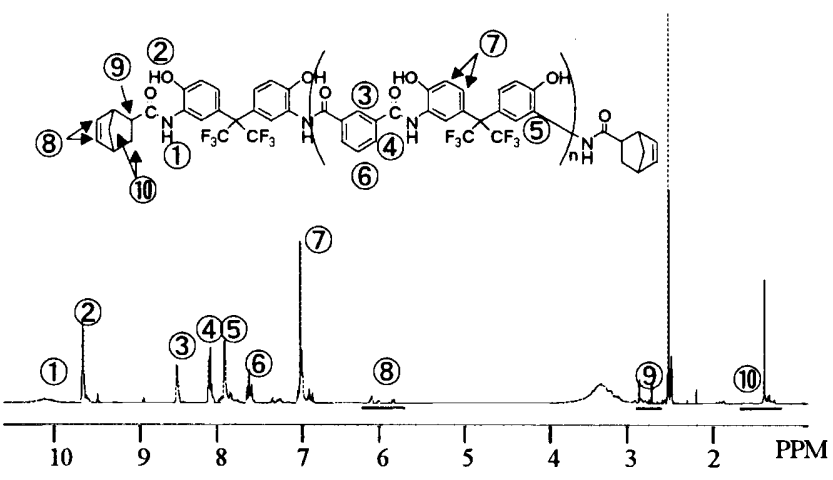

Figure 1. ${ }^{1} \mathrm{H}$ NMR spectrum of polymer 3 in DMSO- $d_{6}$

To obtain a chemical amplification system of PBO precursor, 3 was converted to the corresponding partially $t$-BOC protected polymer 5 by treatment with di-tert-butyl dicarbonate in the presence of DMAP. (eq.2) (Table 1)

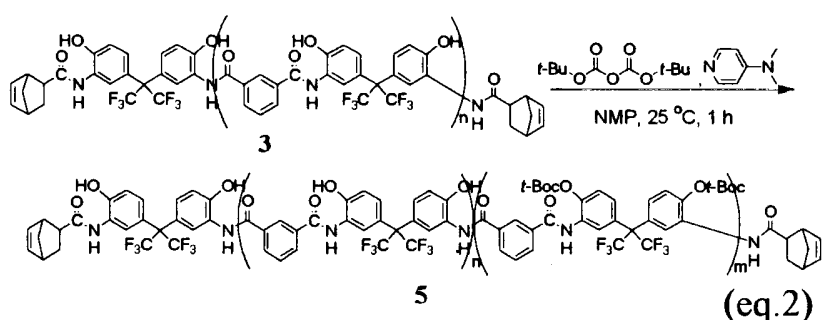

Table 1. Synthesis of polymer 5

\begin{tabular}{ccccc}
\hline Polymer & $\begin{array}{c}\text { Protect feed } \\
t \text {-Boc } / \text { OH }\end{array}$ & Yield (\%) & \multicolumn{2}{c}{ Molecular weight ${ }^{\text {a) }}$} \\
\hline 5a & $80 / 20$ & 95 & 4600 & 1.4 \\
5b & $50 / 50$ & 94 & 4400 & 1.4 \\
5 5 & $30 / 70$ & 94 & 4200 & 1.3 \\
\hline
\end{tabular}

a) Measured by GPC in DMF eluent.

The structure of polymers 5 was fully characterized by IR and ${ }^{1} \mathrm{H}$ NMR spectroscopy. Characteristic tert-butoxycarbonyl and alkyl bands were observed at $1766(\mathrm{C}=\mathrm{O})$ and $2950 \mathrm{~cm}^{-1}(\mathrm{C}-\mathrm{H})$, respectively, in the IR spectrum of 5 . The ${ }^{1} \mathrm{H}$ NMR spectrum showed signals corresponding to tert-butyl protons $(1.4 \mathrm{ppm})$ and aromatic protons (7-8.5 ppm) (Figure 2). The $t$-BOC protected ratios determined by signals at 10.3 (amide) and 1.4 (tert-butyl) in ${ }^{1} \mathrm{H}$ NMR spectrum showed a good agreement with the values from the feed ratios. 


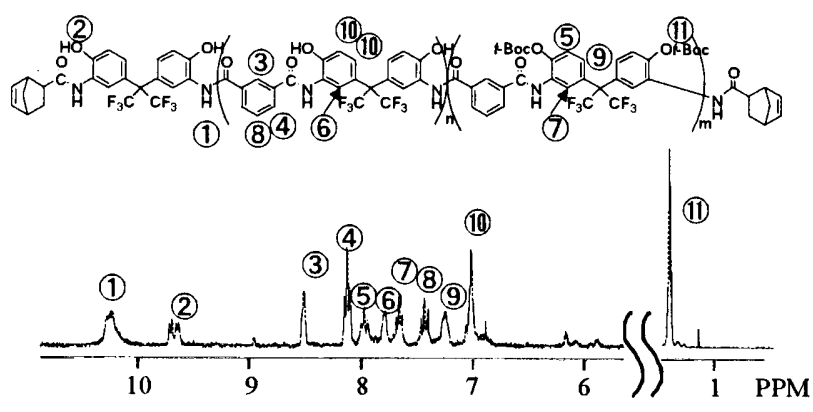

Figure $2 .{ }^{1} \mathrm{H}$ NMR spectrum of polymer $\mathbf{5 b}$ in DMSO- $d_{6}$

\subsection{Lithographic evaluation}

The UV-visible spectrum of polymer $5 b$ film is shown in Figure 3, where a strong absorption at $300 \mathrm{~nm}$ due to $\pi \rightarrow \pi^{*}$ transition of aromatic groups and no absorption above $350 \mathrm{~nm}$ were observed. Thus, DIAS having a strong absorption in the range of $300-420 \mathrm{~nm}$ was selected as a photo-acid generator.

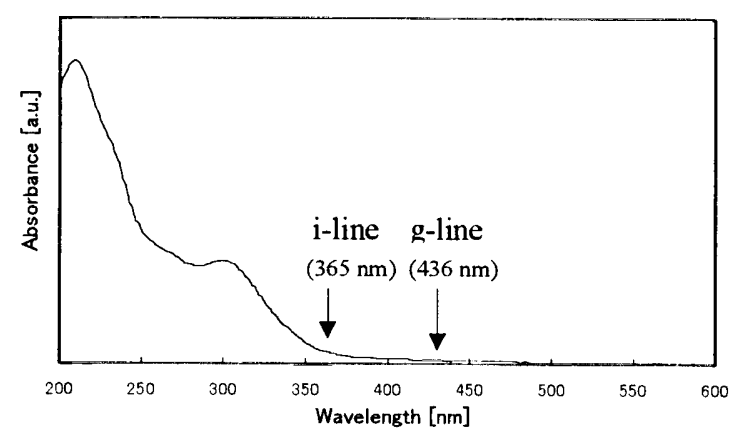

Figure 3. UV-visible spectrum of polymer $\mathbf{5 b}$

To clarify the dissolution behavior of exposed and unexposed areas, the effects of $t$-BOC protecting ratios in polymer 5 and post exposure bake (PEB) temperatures on the dissolution rate in $2.38 \mathrm{wt} \%$ aqueous a tetramethylammonium hydroxide (TMAH) solution were investigated. The films spin-cast on silicon wafers were pre-baked at $80^{\circ} \mathrm{C}$ for $3 \mathrm{~min}$, and then exposed to a filtered super-high pressure mercury lamp $(365 \mathrm{~nm}$, $100 \mathrm{~mJ} \mathrm{~cm}^{-2}$ ). The dissolution rate was estimated by measuring the film thickness after the development.

The effect of $t$-BOC protecting ratios in polymer 5 loading with DIAS after exposure of $100 \mathrm{~mJ} \mathrm{~cm}^{-2}$ and PEB at $120^{\circ} \mathrm{C}$ for 5 min was studied, and the results are illustrated in Figure 4.

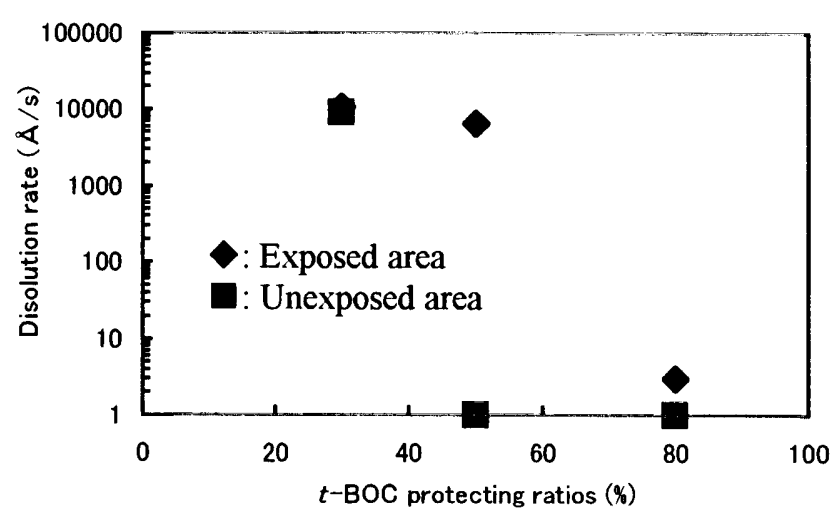

Figure 4. Relationship between dissolution rate and $t$-BOC protecting ratiopolymer 5 with DIAS

The dissolution rate of the unexposed area decreased gradually with increasing the $t$-BOC protection ratios, and reached zero at the $50 \%$ $t$-BOC protection ratio.

To investigate the PEB temperature effect on the dissolution rate, the dissolution rates both of exposed and unexposed areas at various PEB temperatures were measured. The resist was formulated by mixing polymer $5 \mathrm{~b}(70 \mathrm{wt} \%)$ and DIAS (30 wt\%) in ethyl lactate, and the films exposed to $100 \mathrm{~mJ} \mathrm{~cm}^{-2}$ at $365 \mathrm{~nm}$ light were postbaked at temperatures from 100 to $150{ }^{\circ} \mathrm{C}$ for 5 min, and developed with $2.38 \mathrm{wt} \%$ aqueous TMAH developer. The results are shown in Figure 5.

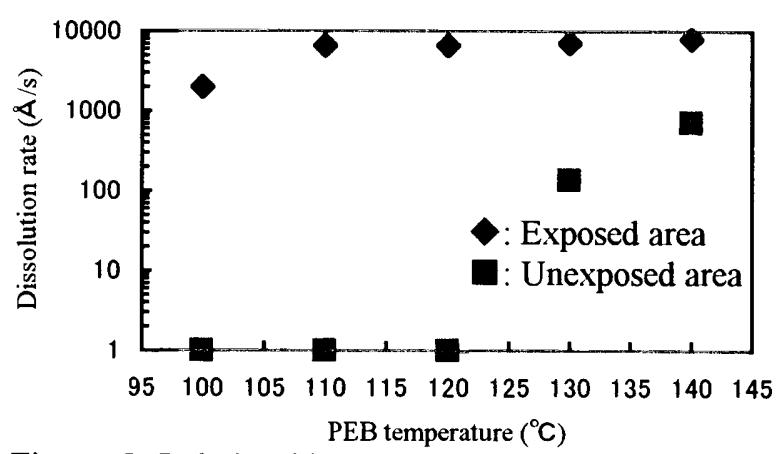

Figure 5. Relationship between dissolution rate and PEB temperature for polymer 5b film containing DIAS

The dissolution rates of the exposed region increased with increasing of PEB temperatures, and that of the unexposed area was rezero below $120{ }^{\circ} \mathrm{C}$. The difference of the dissolution rate between exposed and unexposed parts reached about 10,000 times at $120{ }^{\circ} \mathrm{C}$ for $5 \mathrm{~min}$. Thus, the suitable PEB temperature was determined to be 120 ${ }^{\circ} \mathrm{C}$.

Then, a resist consisting of polymer $\mathbf{5 b}$ and 
DIAS was formulated. The sensitivity curve for a $1.0 \mu \mathrm{m}$-thick polymer $\mathbf{5 b}$ film was consistent with the dissolution behavior studied above, indicating that the sensitivity $\left(\mathrm{D}^{0}\right)$ and contrast $\left(\gamma^{0}\right)$ were 60 $\mathrm{mJ} \mathrm{cm}^{-2}$ and 2.5, respectively (Figure 6).

Figure 7 shows a scanning electron micrograph of the contact printed positive image after exposure of $100 \mathrm{~mJ} \mathrm{~cm}^{-2}$. The resist is capable of resolving a $10 \mu \mathrm{m}$ feature when a $1 \mu \mathrm{m}$ thick film is used.

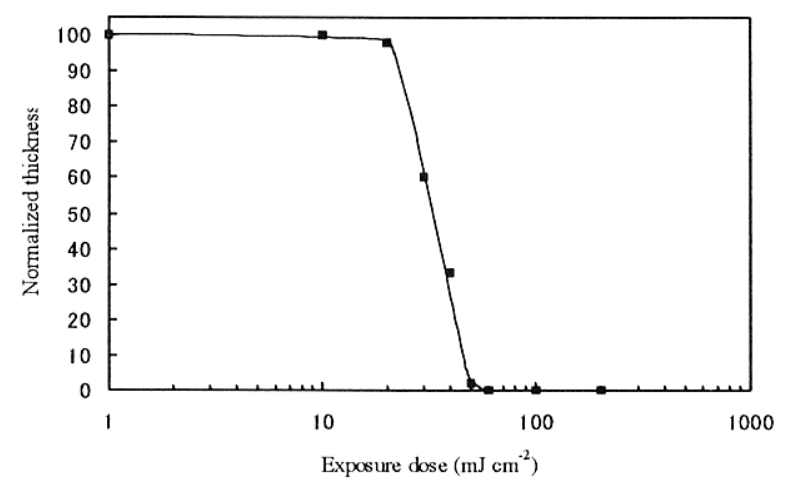

Figure 6.Exposure characteristic curve for polymer $\mathbf{5 b}$ containing $30 \mathrm{wt} \%$ DIAS

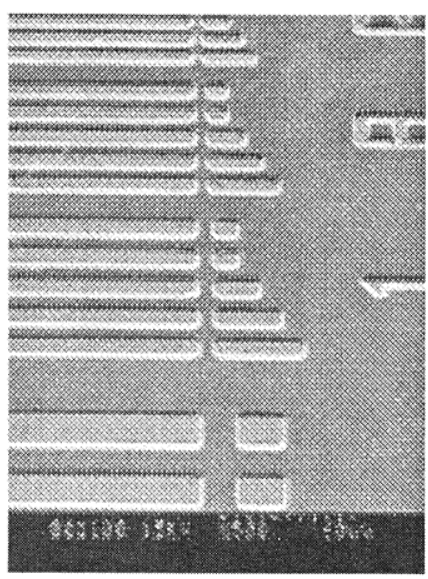

Figure 7. SEM micrograph of pattern from the system consisting of polymer $\mathbf{5 b}$ and DIAS

\subsection{Thermal stability of polymer films}

The positive image in the polymer film was also converted into that of PBO by high-temperature treatment $\left(350^{\circ} \mathrm{C}\right)$ for $1 \mathrm{~h}$. The IR spectra of polymer $5 \mathrm{~b}$ and thermally treated film $\mathbf{6}$ are shown in Figure 8.

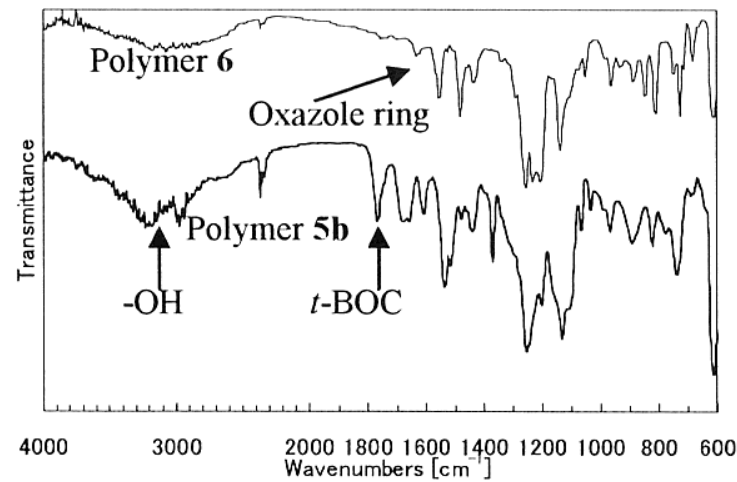

Figure 8 . The IR spectra of polymer $\mathbf{5 b}$ and thermally treated films 6

The characteristic oxazole ring absorption at $1620 \mathrm{~cm}^{-1}$ appeared in polymer 6 , and the absorptions due to the hydroxyl and $t$-BOC groups at 3300 and $1766 \mathrm{~cm}^{-1}$, respectively, in polymer $5 \mathrm{~b}$ disappeared

Figure 9 shows a TGA curve of polymer $5 \mathbf{b}$ film cured at $350{ }^{\circ} \mathrm{C}$ for $\mathrm{lh}$.

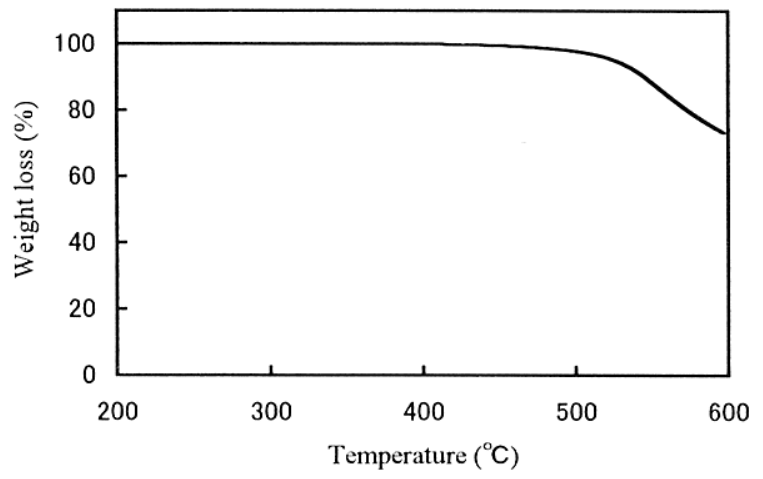

Figure 9. TG curve of polymer $\mathbf{5 b}$ film cured at 350 ${ }^{\circ} \mathrm{C}$ for $\mathrm{lh}$ under $\mathrm{N}_{2}$.

No weight loss of the cured $\mathbf{5 b}$ was observed below $450{ }^{\circ} \mathrm{C}$ and a $5 \%$ weight loss was $530{ }^{\circ} \mathrm{C}$. This curing temperature is higher than that expected for the retro Diels-Alder reaction of norborne group and elimination of water by formation of oxazole ring. Thus, this result indicated that norbornene groups contributed for the cross-linking reaction.

\section{Conclusion}

Norbornene end-capped polymer 3 was prepared by polycondensation of 1 and 2 , followed by treatment with $\mathbf{4}$ as the end-capping agent. Then, polymer 3 was converted to $t$-BOC protected polymer $\mathbf{5}$ by reaction with di-tert-butyl dicarbonate. The resist based on polymer $\mathbf{5 b}$ and 
DIAS showed a high sensitivity $\left(60 \mathrm{~mJ} \mathrm{~cm}^{-2}\right)$ and contrast (2.5) with $365 \mathrm{~nm}$ light. The thermally treated positive image revealed a high thermal stability.

\section{References}

1. Ahne H, Rubner R, and Sezi R., Appl. Surface Sci; 106, 311 (1996)

2. Khanna D N, Mueller W H., Polym Eng Sci, 29, 954 (1989)

3. Kagehisa Y, Takashi H. J. Photopolym. Sci. Tech., 15, 173 (2002)
4. Ebara K, Shibasaki Y, and Ueda M., Polymer, 44, 333 (2003)

5. Toshihiko $\mathrm{O}$, Ken-ichi $\mathrm{K}$, and Tsuguo $\mathrm{Y}$, Macromolecules, 23, 4788 (2003)

6. Willson $\mathrm{C} G$ Bowden $M \mathrm{~J}$ Eds, and Gallagher-Wetmore P M., Proc SPIE, 250, 2438 (1995)

7. W.E. McCormack, "Results of GEAE's Low Cost, Non-MDA PMR-15 Replacement Program", High Temple Workshop, XVI, p.N-1 (1996), Website-http://namis.iitri.org/index2. htm 